\title{
TV Series and Social Media: Powerful Engagement Factors in Mobile Video Games
}

\author{
Fernando de Rada ${ }^{1}$, Asuncion Mochon ${ }^{2 *}$, Yago Saez ${ }^{3}$ \\ ${ }^{1}$ Camilo Jose Cela University, Madrid (Spain) \\ ${ }^{2}$ Applied Economics and Economic History Department, UNED University, Madrid (Spain) \\ ${ }^{3}$ Artificial Intelligence Department, Carlos III University of Madrid, Madrid (Spain)
}

Received 4 October 2018 | Accepted 30 October 2018 | Published 5 November 2018

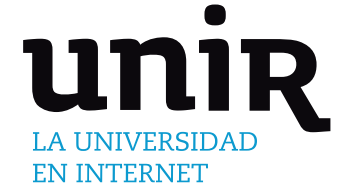

KEYWORDS

Free-To-Play, Video Games, Mobile Games, Game Analytics, Monetization, Customer Retention, Character Identification, TV Series, Social Media, Facebook, Digital Marketing.

DOI: $10.9781 /$ ijimai.2018.11.002

\section{INTRODUCTION}

$\mathrm{T}$ HE mobile video game industry has undergone a deep transformation since the launch of manufacturers' app stores. The barriers to market entry for games and applications have been removed, building up a global and highly competitive space where free-to-play video games have created a multi-million-dollar market based on the sales of virtual goods through in-game micro-purchases. Several companies such as King.com and Supercell report daily incomes of approximately $\$ 5 \mathrm{M}$ and several hundred million Daily Active Users (DAUs) merely from one or two of their free-to-play mobile games [1]-[2]. However, with approximately 500 games launched per day on the iOS digital app store [3], there is an obvious discoverability issue for any brand new content published on it, which hampers the organic growth of its installed base. In such a context, large companies invest heavily in acquiring new players for their games through different in-game advertising networks, which typically work on a best-bid-per-installeduser basis, causing user acquisition costs to skyrocket [4]. Considering that only approximately one to three percent of players will eventually become paying customers [5]-[6], combined with the fact that acquiring each new user can cost in the range of $\$ 3.5$ [7], companies are forced to maximize the income from paying users and, simultaneously, to retain non-paying users as much as possible to convert them or, at worst, to capture some value from them through in-game advertising, their word-of-mouth recommendations, or being cross-linked to other games in the company's portfolio [8].

For this model to be financially viable, it is essential to implement

* Corresponding author.

E-mail address: amochon@cee.uned.es numerous adjustments in the game parameters through different iterations planned over time to finesse the user experience and improve business key metrics. These adjustments typically derive from the analysis of the behavioral telemetry that is recorded in all installed games and that is sent and consolidated on the server side [9].

In this research, we present a novel study, analyzing the effect of a mobile game based on a TV series using real data. To the best of our knowledge, to date, no one has conducted this type of analysis. The mobile game Red Eagle Origins is based on a very famous Spanish TV series: Red Eagle. It was first released in 2009 and is still on the air, already amounting to nine seasons. Although to a certain extent it has been internationally broadcast, there remain many territories where the TV series has not arrived yet, with the video game having been released in such territories. The video game was first released in 2014 for iOS and Android, with over 315.000 downloads (until January 2017), including players from Spain and many other countries. It seems clear that there is going to be a wide gap between the audience exposed to the TV series and the rest of the players in terms of their knowledge of the personality traits and attractiveness of the main characters, the complexity and diversity of the plot, and the setting and historical context. Therefore, first, we propose comparing the metrics gathered from both sets, measuring the impact in terms of user activation, retention, and monetization. Our initial hypothesis is that the players exposed to the TV series are going to have more retention and monetization, though we are uncertain about the real consequences. Second, we aim to analyze the impact of social networks on user behavior comparing regular users and users logged on Facebook. The hypothesis to be tested is whether social networks can help obtain higher-quality users in terms of their retention metrics.

This paper is structured as follows. Section II presents the state of the art. Section III describes the TV series, Facebook and game 
features. The dataset is explained in Section IV. The results comparing Spanish players versus the rest of the world are presented in Section V. Section VI presents the results comparing users involved and noninvolved in social networks, such as Facebook. Section VII analyzes the business impact of the outcome and identifies future marketing strategies. Finally, the conclusions are presented in Section VIII.

\section{RELATED WORK}

Key metrics in the game industry include the following variables: activation, retention and monetization; thus, these features have been widely studied in the literature. However, what makes players engaged? First, we should review this topic to understand the factors that have been identified as influencing players' activation and, ultimately, their retention and monetization.

Finally, we review different concepts such as immersion and character identification in the context of video games, attempting to determine the extent to which these factors have been postulated by studies influencing player enjoyment and engagement.

\section{A. Engagement and Users' Retention and Monetization}

Identifying player motivations is one of the important aspects to be considered with respect to game design [10]. Self Determination Theory (SDT) proposes some general human needs, namely, competence (the need to participate in activities in which we feel capable and effective), autonomy (the need to experience freedom in the activities that we choose), and relatedness (the need to feel connected to other people) [11]. Different motivational models for engagement in video games have been proposed by studies applying SDT principles. Some authors focus on the fundamental psychological needs derived from SDT that gameplay may or may not fulfill, suggesting that "the SDT model of need satisfaction predicts sustained engagement over time, as well as the short-term effects of game activities on players' well-being" [12]. Vallerand et al. conceptualized the term passion [13], which was subsequently used by Wang et al. to examine the underlying psychological processes in digital gaming, with harmonious passion being signaled as the pursuit of engagement in an activity by choice and in harmony with other activities and being strongly associated with intrinsic motivation and positive affect [14].

However, considering the interactive nature of game playing, some other components are necessary to build up an optimum game experience [15]. Information Interaction Theory addresses the communication between the user and the computer interface, with the latter being the main vehicle for the transmission of user experiences [16]. O'Brien and Toms derived from this theory some factors that may be relevant to engagement: affective appeal, challenge, feedback, and perceived control [17].

Perhaps the most influential research on what makes interactive experiences enjoyable was conducted by Csikszentmihalyi in regard to his theory of flow [10], which was originally developed to describe the subjective, emotional state of optimal pleasure that arises when someone is absorbed in any activity that is assumed to be valuable. The idea that optimal experience requires a good balance between the challenges of the game and the skills of the user is central to flow. In addition, such experience should be intrinsically rewarding and immersive, involving a sense of personal control and a high degree of concentration and having clear goals and immediate feedback [18]. Flow theory has been applied by other studies, including [19], [20], and [21], among others.

Uses and Gratifications (U\&G) theory has been applied by [22] to group the reasons that individuals hold for engaging in videogames. An analysis of data derived from focus group interview sessions led to six dominant dimensions that include: arousal, challenge, competition, diversion, fantasy, and social interaction.

On the other hand, some studies have signaled that aesthetics is an important element of engagement [23]; aesthetics has also been linked to the usability and visual appearance of the user interface as well as to the skills and needs of users [24].

[25] elaborated the importance of competitive elements as determinant of enjoyment in playing computer games. They concluded that the wish to be challenged and to compete with others, with the game AI, or even with one's own previous achievements is most likely the single most important motive for interactively entertaining oneself.

With regard to the instruments for measuring engagement, some attempts to standardize the factors that have a significant influence have been made. [26] developed a questionnaire to measure engagement in video games and to empirically test the extent to which such questions could be used to construct a quantitative measure. [27] developed a self-report instrument of user engagement: the User Engagement Scale (UES). [28] extended this work, investigating the use of the UES in the context of game-based environments.

In regard to user retention, presently, given the high competition and low discoverability of the mobile video game market, it is much more expensive to acquire a new user than to retain an older user [29]. Thus, churn (or the number of players dropping out) prediction has become an interesting area of study. [30] used time series' feature representation based on frequency analysis, from the login records extracted from the real data of an online game, for churn prediction modeling. [8] defined the high-value player segment and formulated churn prediction for two live casual social games using in-game virtual currency as an incentive to retain players. Their results showed that giving in-game currency for free does not have an impact on user retention and suggested that players can only be retained by improving their gameplay experience before the churn event occurs. [31] developed a model for churn prediction using data from five free-to-play commercial games across mobile and web-based social-online platforms, defining two different formal models of churn prediction based on game-agnostic features. [9] also used behavioral telemetry data from commercial games, extracting information on how player engagement evolves over time, identifying common patterns and predicting when players' interest in the game is declining. They found that the average player's interest in playing these games follows a decreasing power-law curve.

Finally, [32] used telemetry data from a commercial sports game to encode gameplay patterns for specific players as feature vectors and applied regression to model player retention. Their conclusions signaled that providing players with the correct challenge is a key feature involved in retention.

\section{B. Immersion and Character Identification}

Immersion has been described by many authors as an engaging experience in which players lose awareness of the real world [26]. [33] add some extra characteristics to the previous definition, namely, a distorted sense of time, a high sense of control or a strong involvement perception. Some other authors consider immersion to be specifically related to the psychological experience of engaging with a computer game [21], even if it does not provide the most optimal experience.

Regarding the motivations why people should play video games, immersion has been widely signaled as one of the most important. Bartel's Player Types [34] are a well-known player's taxonomy that has been reviewed by many studies. A good example is an empirically grounded study on player motivations in some popular online games [35], in which a factor analytic approach was taken to group different player motivations into three broad categories, social, achievement and immersion, with the last category being described as a sum of the desire to explore, create a persona linked to a story, customize the appearance 
of the player's avatar, and escape from real-life stress and problems.

The notion of identification with media characters has been widely discussed in media research, well before the emergence of video games. The audience members of a film or TV series or the readers of a novel often become absorbed in the plot and identify with the characters portrayed. There are two different modes of reception typically described by identification researchers: dyadic and monadic. In the dyadic or spectatorship model, media users perceive a social distinction between themselves and the media characters: "viewers observe characters, evaluate them and respond in specific emotional ways" [36]. In this respect, [37] holds that televised drama is entertaining because of the emotional response patterns of viewers; transportation theory [38] acknowledges a strong sense of connection between media users immersed in mediated narratives with characters that are encountered repeatedly over time. Nevertheless, in the monadic approach, audience members experience the interpretation of the plot as though the events were happening to them "in a process that consists of increasing loss of self-awareness and its temporary replacement heightened emotional and cognitive connections with character" [39].

Some studies related to character identification in video games have found a strong correlation between avatar identification and game enjoyment [40]; additionally, [41] find that players of online games who perceive a smaller psychological difference between their avatar and themselves are generally more satisfied and show better retention metrics. Players do not perceive the main character that they are controlling as a distinct social entity: instead, they experience a merging of their own self and the protagonist [36]. This merging process is strongly induced by cognition-based and social dimensions of self-perceptions [39], such as goals, attractiveness, attitudes, successfulness, and respect by others. Players continuously receive and produce information about such dimensions of character attributes. As in interpersonal relationships, in which duration or familiarity is important to the scope of the relationship [42], the longer the audience is exposed to a character, the more likely it will be able to imagine being that character.

Thus regarding our study, it seems reasonable to expect a higher level of character identification in the Spanish subset of players who have been repeatedly exposed to the TV series. This character identification would have an important impact on the game metrics.

\section{Tv Series, Social Network and Game Features}

\section{A. Red Eagle: The TV Series}

Red Eagle is one of the most successful TV series ever broadcast in Spain. This adventure story, frequently peppered with dramatic elements such as underhanded intrigues and torrid romances, is set in the Spanish "Gold Century" around 1660, occurring in the streets of Madrid. The story is based on the wanderings of "Gonzalo de Montalvo", a school teacher who maintains a double life, given that he also embodies Red Eagle, a sort of masked hero. Cared for to its last detail, it has been one of the most expensive TV series ever produced in Spain, with a budget reaching more than a million euro per episode in its early stages [43]. Since its premiere in February 2009, it has been on air for as many as nine seasons, with an average of more than four million spectators and an average audience share of more than $21 \%{ }^{1}$.

\section{B. Red Eagle Origins: The Game}

Red Eagle Origins is the official licensed mobile video game that brings in the best-loved characters of the TV series. The atmosphere of the TV series is recreated by a high-end 3D setting, where a thirdperson camera keeps the main character always centered on the screen,

1 Statistics provided by Globomedia, S.L. allowing players to directly control his/her movements in a highly immersive and interactive game experience. The game was released in February 2014 for Android and iOS platforms and quickly reached very good consumer ratings on both ( 4.73 and 4.20 out of 5 on iOS and Android, respectively) ${ }^{2}$. Upon its release, it also ranked $5^{\text {th }}$ on the Spanish App Store charts in the action games category and reached $5^{\text {th }}$ on the Google Play action games chart, this time coinciding with the beginning of the new season of the TV series in September 2014. Between its release and January 2017, the video game has reached more than 315.000 downloads. Table I depicts the downloads by continent for the analyzed period, differentiating Spanish players. The game has a strong penetration in Africa and the Middle East, mainly in the United Arab Emirates and Egypt, because of the agreement reached by the publisher with the Arabic media group MBC for distribution in its main area of influence.

TABLE I. Downloads by Continent for the Analyzed Period

\begin{tabular}{|c|c|c|}
\hline Continent & Downloads & $\%$ \\
\hline Spain & 1120 & $12 \%$ \\
\hline Rest of the world & 8198 & $88 \%$ \\
\hline Europe & 2348 & $25 \%$ \\
\hline Africa & 4887 & $52 \%$ \\
\hline America & 830 & $9 \%$ \\
\hline Others & 133 & $1 \%$ \\
\hline Total & 9318 & $100 \%$ \\
\hline
\end{tabular}

The game is classified as an "endless runner" type, in which the player-controlled avatar cannot stop its forward momentum, in this case, through the charming streets of $17^{\text {th }}$-century Madrid. Players have to dodge many static and moving obstacles through complicated zones in a fugue that will become increasingly challenging due to its hectic pace. The game difficulty grows gradually as both the complexity of the scenes and the race speed are increased step by step.

The scene consists of a hierarchical structure of blocks that can be can swapped round or combined with each other, forming an infinite, but versatile, circular path. The structure with a higher hierarchy is named a "Round". Three different Rounds are concatenated, with the last Round acting as an infinite loop for those players who reach that far. The Rounds are composed of five Zones: The Village, The Forest, The Castle, The Village Combat Area and The Castle Combat Area (Table II).

TABLE II. COMPOSITION OF RoundS AND ZONES

\begin{tabular}{|c|c|c|}
\hline Round 1 & Round 2 & Round 3 \\
\hline The Village & The Village & The Village \\
\hline $\begin{array}{c}\text { The Village Combat } \\
\text { Area }\end{array}$ & The Forest & $\begin{array}{c}\text { The Village Combat } \\
\text { Area }\end{array}$ \\
\hline The Forest & The Castle & The Forest \\
\hline The Castle & $\begin{array}{c}\text { The Castle Combat } \\
\text { Area }\end{array}$ & The Castle \\
The Forest & The Forest & $\begin{array}{c}\text { The Castle Combat } \\
\text { Area }\end{array}$ \\
\cline { 3 - 3 } & & The Forest \\
\hline
\end{tabular}

During the race, players must not only dodge all types of obstacles but also need to collect some useful objects that will enable their main character to face the different challenges that will be presented. One of these challenges that represents an important novelty in this endless runner genre is the introduction of a "combat area". The character is automatically moved through a narrow hallway, and the player has to defeat the enemies that appear, using different weapons that his/her

2 Gathered from iOS and Google official sites in February and September 2014. 
avatar can improve throughout the game, without causing damage to any innocent passerby. Fig. 1 depicts a screenshot of the video game.
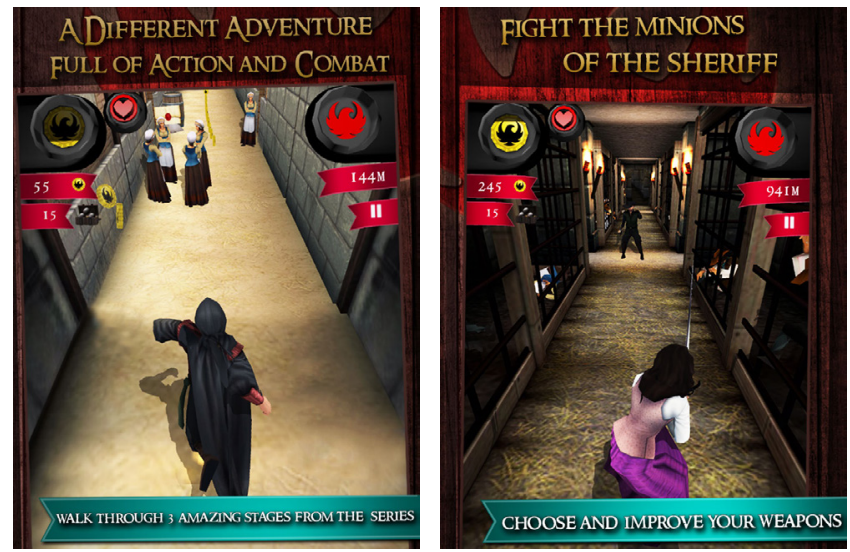

Fig. 1. Screenshots of the third-person game: running action and combat area scenes.

Regarding monetization, since Red Eagle Origins is a free-toplay video game, incomes are based on micro-payments and in-game advertising. First, there is a virtual currency inspired by the Spanish coins of the period ("maravedí"), which players can collect during the race and which are mainly intended to acquire consumables. Then, very engaged players can use real currency to buy customization elements, a different main character with which they tend to identify, or more valuable objects ("power-ups") that let them progress faster in the game.

Further income is derived from in-game advertising. Following each ended game, three different types of ads may be shown: a rewarded video, an interstitial ad, or an ordinary video. Rewarded videos are short pieces typically advertising other games that give a certain amount of virtual currency or any other virtual good to players who complete its visualization. Interstitial and ordinary video ads are full screen images or videos that allow players to directly download the advertised app or game. Fig. 2 shows a screenshot of virtual and real currency in the game.
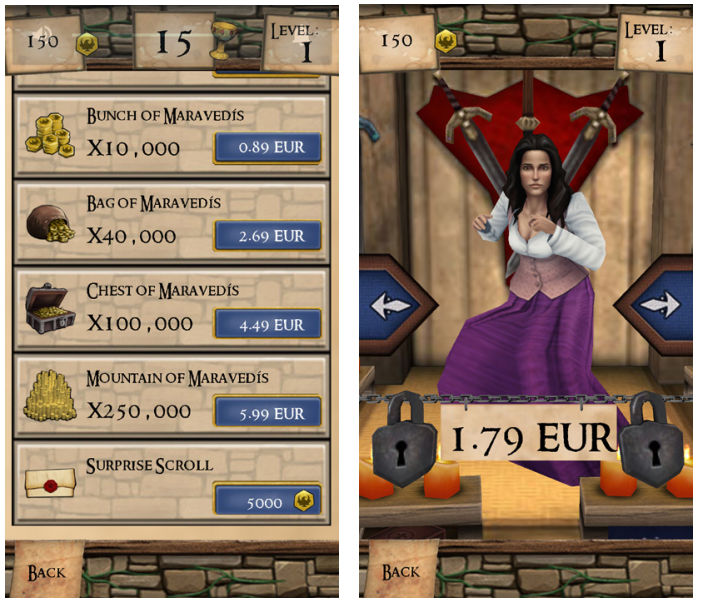

Fig. 2. Screenshots of the in-game store: virtual and real currency

\section{Red Eagle Users in Facebook}

Regarding its social features, the game is integrated with Facebook; thus, players can invite their friends to download the video game from the game itself and compete with them. When logged in and during their run, players will be able to check the farthest point that their Facebook friends have reached, which may become an interesting engaging factor. Moreover, the plot of the game revolves around some scrolls that are randomly dispersed along the way and that contain valuable details of the main characters of the TV series. Players will be able to collect them during gameplay and swap duplicates with their Facebook friends. The objective of this social feature is to improve user acquisition and foster player engagement.

\section{Red Eagle Origins Data Set}

The Red Eagle Origins analytics engine, developed by Wildbit Studios, is a two-fold distributed instance. On one hand, it runs in each client installation, collecting local data. On the other hand, there is a single server environment that synchronizes the data with all client instances, acting as a global data warehouse. Synchronization is bidirectional, which means not only that the server is able to receive all behavioral data from client installations but also that such client instances may be updated with the specific configuration parameters that the game will be applying from that moment forward.

The analytics engine can gather behavioral data even when the device is offline because such data are stored first in a local database. In this manner, the system can locally store an enormous amount of both transactional and operational data for each user, covering all events occurring in each game session. All local data are regularly uploaded to the server side, where everything is consolidated in one dataset that currently stores approximately 20 million user variables from more than 9.3 million games and more than 5.6 million sessions.

The data can be classified into two large clusters: individual user data and aggregated metrics.

\section{A. Individual User Data}

The user data are divided into five groups, depending on the goals pursued:

1. Identification: Allows the system to link each user dataset with a unique player, including information such as: installation id, country, language, installation time or operating system.

2. Activation: Information related to the players' activity during the first week or after a certain number of games played to identify whether they have had a minimum exposure to the game features. Considering the typology of this video game, which possesses a straightforward mechanics, we have fixed a minimum threshold of 10 games played to evaluate users' activation. The variables included in this group are: installation date, last activity time, number of games played or retention rate (percentage of returning users measured at a regular interval, typically weekly or monthly).

3. Engagement / Retention: Addresses the user's engagement level, measuring player frequency, progression and uses of the game features. This data set includes the largest number of variables, among which are: the retention rate for longer periods (typically 30 days), recency (time since the last entry into the game), number of sessions and games played, number of total meters travelled, maximum meters travelled in a single game (high score), experience level reached, number of scrolls, calices and coins collected, number of skills used, and characters unlocked.

4. Monetization: This group includes key variables to measure the game financial trend. All transactional data are recorded from both the virtual economy and the real economy, such as: virtual and real currency expenditure, virtual items sold, skills improved, and the number of ads shown and clicked by players.

5. Social features or viralization: Comprises all variables related to the integration with Facebook such as number of players who have logged in, number of shares, and number of scrolls shared, among others. 


\section{B. Aggregated Metrics}

There are many aggregated metrics that are built based on all the gathered user data and cooked on the server side. Some of these metrics are typically taken as Key Performance Indicators (KPIs) in the video game and other digital industries. Some of these KPIs are: number of DAUs, Monthly Active Users (MAUs), the Conversion Rate (CVR) to become a paying user, Average Revenue Per User (ARPU), Average Revenue Per Paying User (ARPPU), or Revenue Per Mille (RPM), related to in-game ads.

The dataset used in the present study includes players who installed the game for the first time from May 5 to July 15, 2016, and registered their behavioral data until September 2, 2016. This time frame allows for at least 49 days of operation for those users who installed the game on July 15,2016 . Table III shows a summary of the raw dataset, which includes 9318 players, of whom 1120 are Spanish players and 8198 are from the rest of the world.

TABLE III. Summary of RaW Dataset

\begin{tabular}{|c|c|c|}
\hline Dataset & Spanish players & Rest of the world \\
\hline $\begin{array}{c}\text { Installation } \\
\text { interval }\end{array}$ & May 5 to July 15, 2016 & May 5 to July 15, 2016 \\
\hline $\begin{array}{c}\text { Time frame for } \\
\text { the experiment }\end{array}$ & $\begin{array}{c}\text { May 5 to September 2, } \\
2016\end{array}$ & $\begin{array}{c}\text { May } 5 \text { to September 2, } \\
2016\end{array}$ \\
\hline $\begin{array}{c}\text { Minimum period } \\
\text { of operation }\end{array}$ & 49 days & 49 days \\
\hline \# of players & 1120 & 8198 \\
\hline
\end{tabular}

As we have observed, the dataset includes more than several hundred attributes pertaining to five different groups. We have identified some appropriate variables from the identification, activation, engagement and monetization groups that allow us to focus on the meaningful data to compare both subsets. Table IV summarizes the final attribute set for the experiment.

TABLE IV. Final Attribute Set

\begin{tabular}{|c|c|}
\hline User Data Group & Final Attribute Set \\
\hline Identification & Installation ID, Country, Installation time \\
\hline Activation & \# games played, Last activity time \\
\hline Engagement & $\begin{array}{c}\text { \# games played, Maximum meters travelled, Total } \\
\text { meters travelled, Lifespan }\end{array}$ \\
\hline Ads monetization & $\begin{array}{c}\text { \# in-game ads shown, \# clicks on ads, \# ads } \\
\text { unavailability }\end{array}$ \\
\hline
\end{tabular}

\section{TV SERIES IMPACT}

In this section, we evaluate whether there is a significant difference between the audience exposed to the TV series and the rest of the players in terms of the initial interest that they show in the game (activation), in addition to their retention and monetization metrics.

\section{A. Activation}

We consider a player to be activated after he/she has played 10 games. We have assessed this threshold evaluating the average maximum number of meters (high score) reached by players who have played fewer than 10 games, which turns out to be 772.9 meters for the Spanish subset and 763.8 for the rest of the world. Considering that the first zone - "The Village" - has a total length of 1012 meters, the players of both segments have covered, on average, approximately three-fourths of the total distance, in this manner being fairly exposed to the main game mechanics.
Table V summarizes the churn metrics for each subset measuring the following activation variables: number of players who have played fewer than 10 games and number of players who dropped out before 7 days (R7). The results show that the rest of the world segment has a higher rate of early dropout or churn than the Spanish segment in terms of games $(79 \%$ versus $61 \%)$ and number of days played ( $89 \%$ versus $80 \%$ ). This outcome suggests that having players exposed to the TV series has a positive effect on the players' activation.

TABLE V. Churn Metrics (EArly drop)

\begin{tabular}{|c|c|c|c|}
\hline & $\begin{array}{c}\text { Spanish } \\
\text { players }\end{array}$ & $\begin{array}{c}\text { Rest of the } \\
\text { world players }\end{array}$ & Total \\
\hline Total \# players & 1120 & 8198 & 9318 \\
\hline \# players games $<10$ & 683 & 6474 & 7157 \\
\hline Percentage & $61 \%$ & $79 \%$ & $77 \%$ \\
\hline \# players drop out before R7 & 899 & 7267 & 8166 \\
\hline Percentage & $80 \%$ & $89 \%$ & $88 \%$ \\
\hline
\end{tabular}

\section{B. Engagement/Retention}

For an evaluation of engagement and retention, we focus on only those players who can be considered activated, i.e., those who have played more than 10 games. For the retention metrics, we have selected four variables that may indicate the extent to which players are engaged in the game: number of games played, maximum meters travelled, total meters per user and lifespan. Table VI shows the results for these variables.

The results show that users exposed to the TV series, that is, Spanish players, have a higher retention rate for all variables tested: they play more games, have a higher maximum number of meters, travel more meters, and play for more days than players from the rest of the world. These variables do not follow a normal distribution ${ }^{3}$; thus, we have used nonparametric tests to check whether the differences between both sets are significant. Because we do not want our test to be sensitive to differences in the general shapes of the distributions, we discard the Kolmogorov-Smirnov (KS) test and, instead, perform the Mann-Whitney $U$ test, which tests for differences in the location of two samples [44]. The results obtained indicate that the differences are significant for all variables $(p<0.05){ }^{4}$

We have graphically compared the normalized data by means of their density plots; see Fig. 3. The density plot for the number of games played is depicted in Fig. 3.a. It shows that the number of players who drop out early is higher in the rest of the world set. Nevertheless, as we move toward the right-hand side of the curve, the Spanish segment density plot is always above, showing the stochastic dominance that the $U$ test revealed. Similarly, at the beginning, the rest of the world density plot is above the Spanish set for the maximum number of meters (Fig. 3.b), total meters (Fig. 3.c) and lifespan (Fig. 3.d), but as we spread toward the right-hand side of the figure, the Spanish plot is always above. These figures confirm that players exposed to the TV series are more engaged, most likely because they identify with the TV characters, increasing the retention ratio.

This difference in players' engagement is ultimately determined by the retention rate curve, which measures what percentage of players return to the game throughout the days since their installation date (Fig. 4).

Again, performing a Mann-Whitney $U$ test, we can verify that the differences between both sets are significant, where a $p$-value = 0.0001063 confirms the dominance of the Spanish set in terms of the retention rate. Typically, the retention rate is measured at days one

3 It has been verified performing a Shapiro-Wilk normality test, obtaining p-values well below 0.05 for both segments in all variables.

4 Number of games $p=7.98 \mathrm{e}-13$, Max meters $p=1.313 \mathrm{e}-15$, Total meters $p=$ 2.2e-16 and Lifespan $p=1.711 \mathrm{e}-05$. 
(R1), seven (R7), and thirty (R30), with R1 accounting for a very early drop out, R7 being the activation threshold, and R30 being the long-run reference metric. Although we observe similar values at R1 for both sets (R1_ES $=75.5 \%$; R1_REST $=74.1 \%$ ), as we progress throughout the number of days since installation, the retention values tend to diverge, with differences of approximately $13 \%$ and $12 \%$ for R7 and R30, respectively, as shown in Table VII.

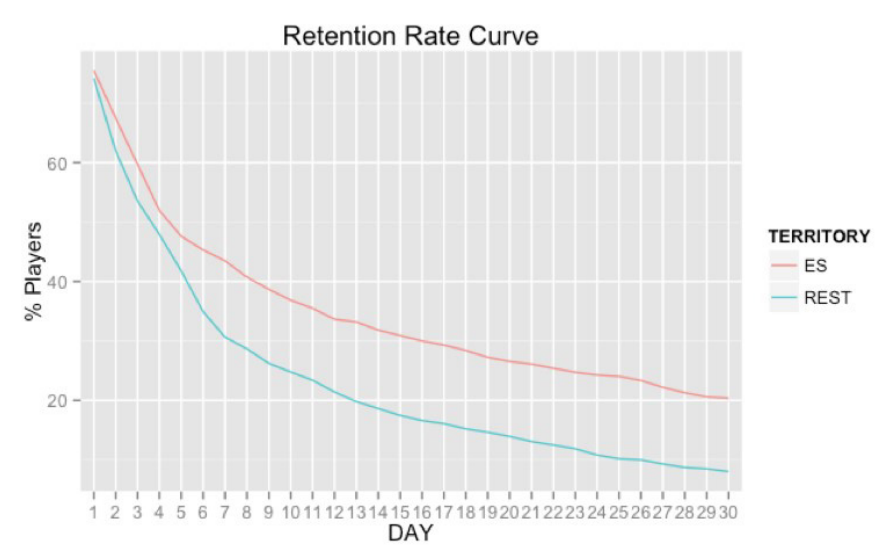

Fig. 4. Graphic comparison of the retention rate curves.

TABLE VII. RETENTION RATE

\begin{tabular}{|c|c|c|}
\hline & Spanish players & Rest of the world players \\
\hline R1 & $75.5 \%$ & $74.1 \%$ \\
\hline R7 & $43.5 \%$ & $30.6 \%$ \\
\hline R30 & $20.4 \%$ & $8 \%$ \\
\hline
\end{tabular}

\section{Ads Monetization}

An important piece of information for the mobile video game industry is knowing whether the value of acquired users can also depend on factors such as character identification by means of a TV series. Therefore, in this section, the impact of being exposed to the TV series is measured in terms of monetization.

Ad performance is typically measured by impressions through the RPM metric ${ }^{5}$. Nevertheless, in the Red Eagle Origins video game, the ad network provider is Chartboost, which measures advertisers in terms of bid $^{6}$ per click or install ${ }^{7}$ (instead of per impression). Chartboost RPM is a combination of an advertising campaign's Install Rate (IR) ${ }^{8}$, ClickThrough-Rate (CTR) ${ }^{9}$, and bid. In this section, we include the CTR variable to measure ad performance.

Furthermore, as a publisher, the goal is to maximize earnings by showing as many ads as possible. Hence, the first variable analyzed is the number of ads shown. We could simply count the number of times any ad is shown to a player, but there is not always an ad available when the game is ready to show it. Nevertheless, there is a variable in the dataset that measures the number of times that an ad request is not fulfilled per player. Thus, we establish a new variable that adds up the number of ads shown plus the number of times that an ad is requested and not fulfilled. This variable represents the ads chance and

5 Earnings that accrue for every 1000 impressions received.

6 Advertisers' with higher bids take priority in showing their ads on the publishers' available inventory.

7 Mobile networks commonly bill advertisers on a CPI (Cost per Installation) basis.

8 The Install Rate of an ad campaign means how many clicks on an ad it takes to lead to an installation of an app.

9 The ratio of users who click on a specific link to the number of total users who view an ad. has allowed us to make a comparison between both segments in terms of their ad potential revenue.

Table VIII. Advertising Metrics

\begin{tabular}{|r|c|c|}
\hline & Spanish players & Rest of the world players \\
\hline CTR & & \\
\hline Mean & 7.02 & 11.82 \\
\hline 5\% Trimmed Mean & 4.04 & 7.95 \\
\hline Standard Deviation & 17.57 & 23.67 \\
\hline Ads Chance & & \\
\hline Mean & 65.41 & 34.09 \\
\hline 5\% Trimmed Mean & 47.87 & 25.47 \\
\hline Standard Deviation & 113.95 & 64.77 \\
\hline
\end{tabular}

Table VIII shows the Ads Chance and CTR variables by set. We perform a $U$ test to observe whether there is a significant difference between the two segments in regard to the Ads Chance variable, and the test confirms that the Spanish region shows a greater proportion of the ad impacts available, with a $p$-value $<2.2 \mathrm{e}-16$. We also check how both segments behave in terms of CTR. We perform another U test, and with a $p$-value $=0.00081$, the test confirms that contrary to the other variables measured, the rest of the World segment is more willing to click on the ads displayed. Fig. 5 graphically shows these results. This interesting finding may be motivated by several reasons such as the quality of the ad server or a different user behavior based on the user's citizenship.

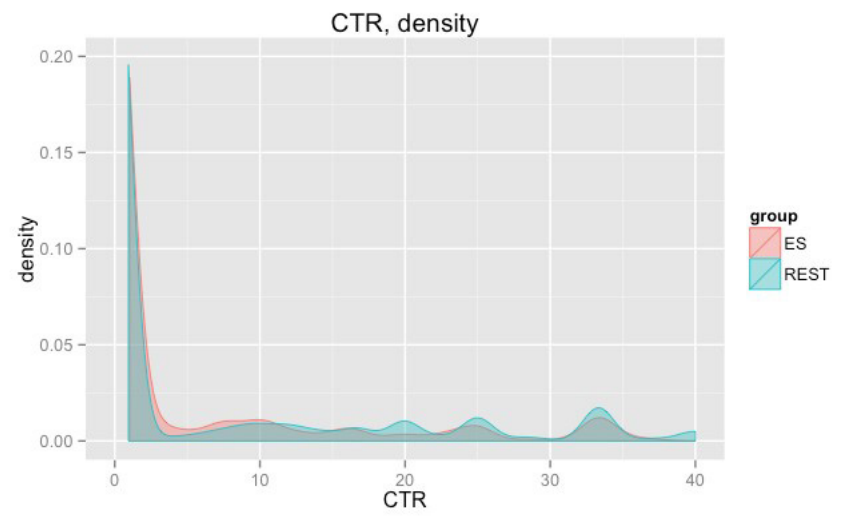

a. CTR

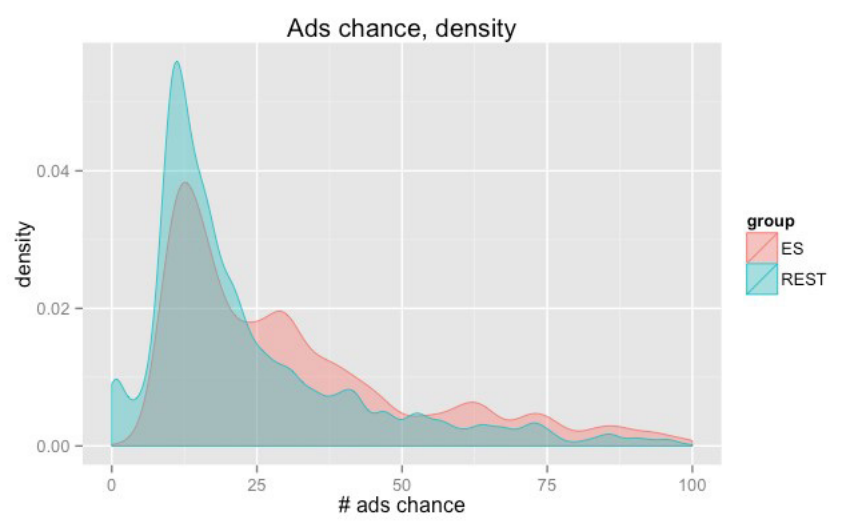

b. Ads chance

Fig. 5. Densities of monetization variables for Spanish players (ES) and the rest of the world players (REST). 


\section{SOCIAL NETWORK IMPACT}

In this section, we have divided the data set into two subsets: players logged on Facebook and players non-logged on Facebook. Users' behavior for these two sets have been compared in terms of activation, retention and monetization.

\section{A. Activation}

The churn metrics for each subset are depicted in Table IX. The results show that users who are logged on Facebook are more likely to become active users. They have lower early drop metrics both in terms of number of games $(63 \%$ versus $78 \%$ ) and dropping out within the first 7 days ( $83 \%$ versus $88 \%)$.

TABLE IX. Churn Metrics (EARLY DROP)

\begin{tabular}{|c|c|c|c|}
\hline & $\begin{array}{c}\text { Logged on } \\
\text { Facebook }\end{array}$ & $\begin{array}{c}\text { Not logged } \\
\text { on Facebook }\end{array}$ & Total \\
\hline Total \# players & 631 & 8687 & 9318 \\
\hline \# players games $<10$ & 396 & 6761 & 7157 \\
\hline Percentage & $63 \%$ & $78 \%$ & $77 \%$ \\
\hline $\begin{array}{c}\text { \# players drop out } \\
\text { before R7 }\end{array}$ & 522 & 7645 & 8167 \\
\hline Percentage & $83 \%$ & $88 \%$ & $88 \%$ \\
\hline
\end{tabular}

\section{B. Engagement/Retention}

Table X shows the results for both subsets in terms of: number of games played, maximum meters travelled, total meters per user and lifespan. For all variables included, the users logged on Facebook turn out to be higher-quality users because, on average, they play more games, have a higher maximum meter score, have more total meters, and have a longer lifespan. None of these variables follows a normal distribution; thus, non-parametric tests have been performed to check whether the differences are significant. The Mann-Whitney $U$ test indicates that the differences in both sets are significant ${ }^{10}$.

TABLE X. Retention Metrics

\begin{tabular}{|c|c|c|}
\hline & $\begin{array}{c}\text { Logged on } \\
\text { Facebook }\end{array}$ & $\begin{array}{c}\text { Not logged on } \\
\text { Facebook }\end{array}$ \\
\hline Total players & 631 & 8687 \\
\hline Activated players (games $\geq 10$ ) & 235 & 1926 \\
\hline$\%$ & $37 \%$ & $22 \%$ \\
\hline \# games played Mean & 23.19 & 11.51 \\
\hline 5\% Trimmed Mean & 11.44 & 6.17 \\
\hline Standard Deviation & 88.15 & 36.26 \\
\hline Max meters Mean & 1418.7 & 961.1 \\
\hline 5\% Trimmed Mean & 1265.03 & 883.64 \\
\hline Standard Deviation & 1267.6 & 934.53 \\
\hline Total meters Mean & & \\
\hline 5\% Trimmed Mean & 8456.62 & 3510.62 \\
\hline Standard Deviation & 134993.8 & 44499.74 \\
\hline Lifespan (days) Mean & & \\
\hline 5\% Trimmed Mean & 6.28 & 3.89 \\
\hline Standard Deviation & 3.76 & 1.89 \\
\hline & 14.54 & 12.56 \\
\hline
\end{tabular}

Fig. 6 depicts a graphical comparison of the normalized data by means of their density plots in terms of the number of games played (Fig. 6.a) maximum meters reached (Fig. 6.b), total meters travelled

10 The p-values obtained for all of these variables fall below 2.2e-16.
(Fig. 6.c) and lifespan (Fig. 6.d). These figures confirm that players logged on Facebook are likely to be more involved in the game, most likely because they are enabled to compete with their friends and to share and swap duplicate scrolls with each other.

As with our analysis of the TV series impact above, we compare the retention rate curves of Facebook vs. non-Facebook players, and we observe that there is a significant leap between both curves (Fig. 7).

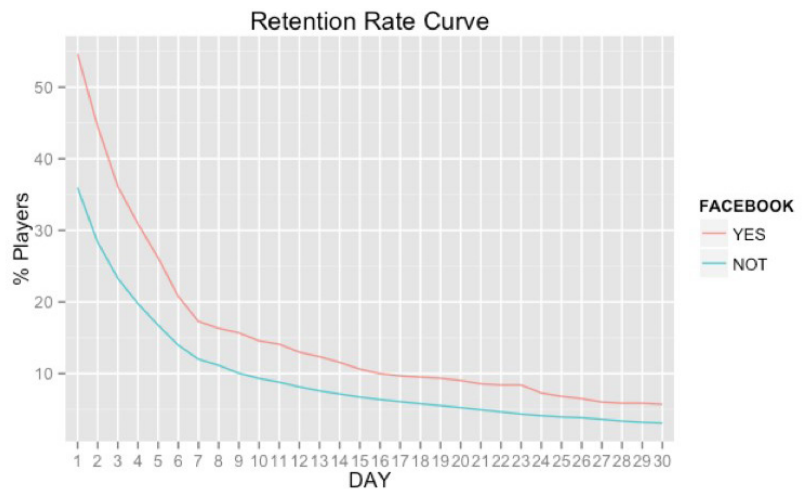

Fig. 7. Graphic comparison of the retention rate curves from players logged vs. not logged on Facebook.

Performing a Mann-Whitney U test, we verify that these differences are significant, with a $p$-value $=0.001377$ that confirms a higher retention rate profile for the Facebook segment. If we take a more detailed look at the standard retention metrics, i.e., R1, R7 and R30, we observe that players logged on Facebook are much more willing to pass the day one retention threshold, giving the game a chance; in the R7 metric, there is also a good advantage for Facebook players, and the percentage of Facebook users who continue to play in the long-term retention metric, R30, is double that of those not logged on Facebook, as shown in Table XI.

TABLE XI. RETENTION RATE

\begin{tabular}{|c|c|c|}
\hline & Logged on Facebook & Not logged on Facebook \\
\hline R1 & $54.7 \%$ & $35.9 \%$ \\
\hline R7 & $17.3 \%$ & $12 \%$ \\
\hline R30 & $5.7 \%$ & $3.1 \%$ \\
\hline
\end{tabular}

\section{Ads Monetization}

As with our above analysis of the players who have been exposed to the TV series, we can assess the ads monetization metrics for players logged on Facebook vs. those who are not. Doing so allows us to make a comparison between both segments in terms of their ad potential revenue. Table XII shows the outcome of the CTR and Ads Chance measured variables.

Table XII. Advertising Metrics

\begin{tabular}{|r|c|c|}
\hline & Logged on Facebook & $\begin{array}{c}\text { Not logged on } \\
\text { Facebook }\end{array}$ \\
\hline CTR & & \\
\hline Mean & 7.97 & 6.17 \\
\hline 5\% Trimmed Mean & 3.74 & 2.19 \\
\hline Standard Deviation & 22.3 & 20.21 \\
\hline Ads Chance & & \\
\hline Mean & 23.01 & 10.19 \\
\hline 5\% Trimmed Mean & 10.62 & 5.24 \\
\hline Standard Deviation & 94.21 & 33.94 \\
\hline
\end{tabular}

We perform a $U$ test to observe whether there is a significant difference between the two segments in regard to the Ads Chance 
variable, and the test confirms that the Facebook segment shows a greater proportion of the available ad impacts, with a $p$-value $<2.2 \mathrm{e}-16$. In terms of CTR, we perform another $\mathrm{U}$ test, with a $p$-value $=4.397 \mathrm{e}$ 05 . The test confirms that the Facebook segment is more willing to click on the ads displayed. Fig. 8 graphically shows these results.

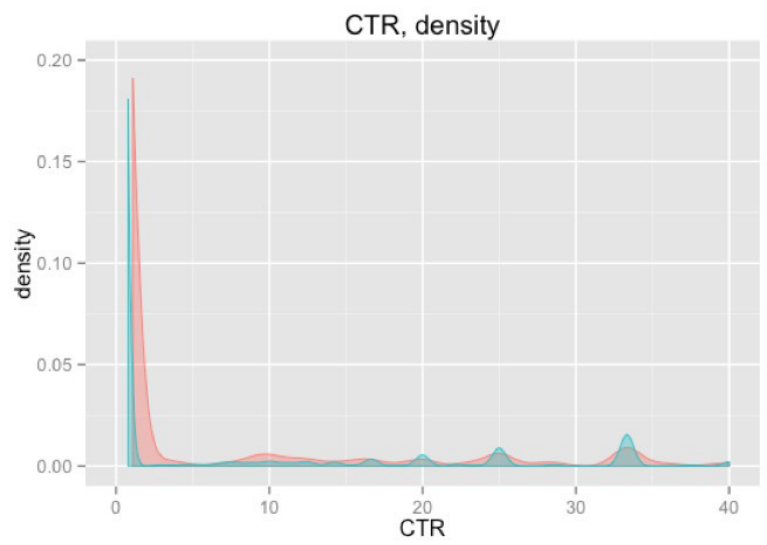

a. CTR

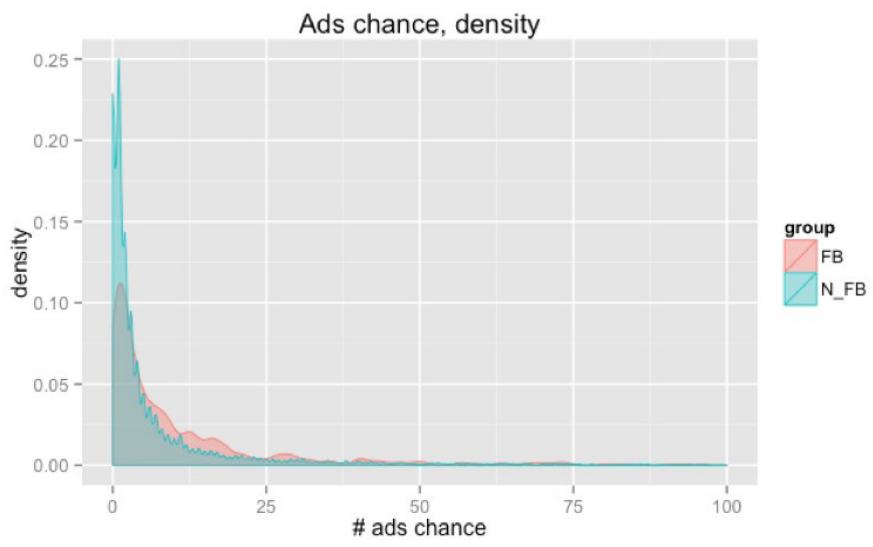

b. Ads chance

Fig. 8. Densities of monetization variables for users logged and not logged on Facebook.

\section{BUSINESS IMPACT}

In this section, we discuss the results obtained from the business value point of view. We check to what extent the differences observed in the behavior of each segment of players imply differences in revenues. To do so, we have focused on assessing the income derived from in-game advertising during the time frame of the experiment. The variable selected to compare both segments is the Life Time Value (LTV), computed as the product of the Average Revenue Per Daily Active User (ARPDAU) ${ }^{11}$ times the Lifespan.

Table XIII compares the TV series impact over these variables. We observe a great difference in between both segments: Spanish players show a LTV increase of $192 \%$ compared to the Rest of the world.

11 The ARPDAU is a standard metric in the industry and allows game designers and managers to follow the income evolution on a daily basis, frequently in order to monitor the changes applied on the fly to one or some of the game parameters [45]. It is calculated as: $A R P D A U=R P M * A D A O / 1000$, where the average RPM for such period was $\$ 1.09$ and the Average Daily Ads Opportunity (ADAO) per active user is calculated as ADAO = AdsOpp / Lifespan.
TABLE XIII. TV SERIES BusINESS IMPACT

\begin{tabular}{|c|c|c|}
\hline & Spanish players & Rest of the world players \\
\hline Lifespan in days (mean) & 18.15 & 9.19 \\
\hline Ads Opp (mean) & 65.41 & 34.09 \\
\hline ADAO & 3.604 & 3.709 \\
\hline ARPDAU & 0.0039 & 0.0040 \\
\hline LTV & 0.071 & 0.037 \\
\hline
\end{tabular}

When the same calculations are performed to compare those players logged and not logged in Facebook, we get an even more significant increase of $226 \%$ on LTV of logged users, see Table XIV.

TABLE XIV. Social Media Business ImPaCT

\begin{tabular}{|c|c|c|}
\hline & Logged on Facebook & $\begin{array}{c}\text { Not logged on } \\
\text { Facebook }\end{array}$ \\
\hline Lifespan in days (mean) & 6.28 & 3.89 \\
\hline Ads Opp (mean) & 23.01 & 10.19 \\
\hline ADAO & 3.664 & 2.619 \\
\hline ARPDAU & 0.0040 & 0.0028 \\
\hline LTV & 0.025 & 0.011 \\
\hline
\end{tabular}

We have seen in previous sections how being exposed to the TV series, or being logged on Facebook when playing the game, both have a significant positive impact on the retention metrics, increasing the users' lifespan. From the manager perspective, in the free-to-play business model the goal is to capture as much value as possible from users that have got the video game for free. So, maximizing the retention metrics could have a two fold benefit: on the one hand, the longer the players stay in the game, the higher opportunities they will have to bring their friends to share the same experience, reducing in turn the marketing User Acquisition Cost (UAC) through this "viralization" mechanism. On the other hand, we have seen that a longer lifespan translates into greater LTV derived from higher exposure times to ingame advertising, increasing final revenues. With the analysis done, we propose the following marketing strategies that could be implemented in free-to-play games:

- A video game company could be interested in achieving a licensing agreement with the owners of a TV series whose main audience overlaps with the video game target, as our experiment reveals that the LTV of players will get an increase of $192 \%$.

- Use incentives to encourage players to log on Facebook or similar social network, as their LTV shall exceed $226 \%$ of not logged users. These incentives could be giving some virtual currency or digital goods for free.

\section{CONCLUSIONS}

In this study, we analyze the free-to-play video game industry from a novel perspective. We measure the impact of TV series and social networks on the main game metrics: activation, retention and monetization. To meet this challenge, a database of real users involved in the "Red Eagle Origins" game is used.

The first hypothesis to be tested regarding character identification involves checking whether being exposed to the TV series "Red Eagle" influences the initial interest that players show in the game (activation) and their retention and monetization metrics. The results indicate that Spanish players who have been exposed to the TV series are higherquality users than players from the rest of the world who have not been exposed to the TV series.

The Spanish subset has a lower rate of "churn" or early dropout than the rest of the world. To some extent, this difference may be due to various cultural and socio-psychological factors regarding the affinity 
with the historic theme and the game typology itself. However, again, the studies noted above suggest that being exposed or not to the TV series could be one of the determinant factors in the initial degree of interest shown by players. The results obtained confirm previous studies that suggest that being exposed or not to the TV series could be a determinant factor in the initial degree of interest shown by players.

The retention metrics show that the Spanish segment of players plays more games, stays in the game for longer and travels more meters than the rest of the world segment. These results seem to suggest that being exposed to the TV series is a key factor for retention because of the extra motivation that character identification provides to players.

Regarding monetization through in-game ads, the results show that as Spanish players have in general higher retention metrics, ads also have more chances to be displayed to them, generating more revenue, meaning that Spanish players have more business value. Although it has been verified that the rest of the world segment has a higher CTR, this difference in behavior may be due to various factors, such as the suitability of the displayed ads or the average willingness of players from different territories to click on any ad. Regardless of the cause, it should not depend on being exposed or not to the TV series, given that the ads offered are related to other games or apps, and in this case, CTR can be interpreted as more of a geographical or socio-cultural dependent variable.

The second hypothesis tested in the present work concerns whether integrating a social network into the game mechanics may have an impact on user behavior, improving the quality of players that make use of these social capabilities. In this analysis, the database has been divided into players logged and not logged on Facebook. The results reveal that there is a significant impact on all analyzed metrics.

Players logged on Facebook are more involved in the game, given that they can compete with their friends and share and swap duplicate scrolls with each other. These factors have a positive impact in terms of activation and retention because they present lower dropout metrics and, therefore, higher retention curves. These users play more games, travel more meters and play for longer periods. In terms of monetization, these users also have higher business value because they show higher CTR and Ads Chance values.

Given the characteristics of the free-to-play video game industry, it is crucial to identify the variables that have a significant impact on the business model. In this study, we show that players exposed to a TV series linked to the video game identify with the main characters, improving the users' quality. Furthermore, players logged on social networks such as Facebook experience higher values in terms of activation, retention and monetization, thereby substantiating that playing and sharing with friends reinforce engagement.

\section{REFERENCES}

[1] D. Takahashi, "Candy Crush Saga maker King reports strong Q1 with $\$ 569 \mathrm{M}$ in adjusted revenue and 61 cents-a-share profit," Venturebeat.com, 2015.

[2] J. Diaz, "Supercell Makes \$5 Million Per Day Off Clash Of Clans," AndroidHeadlines, 2015.

[3] K. Graft, "500 games launched per day on iOS last year (and other digital sales facts)," Gamasutra, 2015.

[4] D. Takahashi, "User acquisition costs go up, up, and away in August," Venturebeat.com, 2015.

[5] T. McCalmont, "How Do I Know I Have a Healthy Game?," Gamasutra, 2013.

[6] M. Callaghan, N. McShane, and A. G. Eguíluz, "Using game analytics to measure student engagement/retention for engineering education," in Remote Engineering and Virtual Instrumentation (REV), 2014 11th International Conference on, 2014, pp. 297-302.

[7] M. Minotti, "User acquisition costs up 26\% in February after January's drop, Fiksu finds," Venturebeat.com, 2016

[8] J. Runge, P. Gao, F. Garcin, and B. Faltings, "Churn prediction for highvalue players in casual social games," in 2014 IEEE Conference on Computational Intelligence and Games, 2014, pp. 1-8.

[9] C. Bauckhage, K. Kersting, R. Sifa, C. Thurau, A. Drachen, and A. Canossa, "How players lose interest in playing a game: An empirical study based on distributions of total playing times," in 2012 IEEE Conference on Computational Intelligence and Games (CIG), 2012, pp. 139-146.

[10] M. Csikszentmihalyi, Flow: the psychology of optimal experience. Harper Perennial, 1990.

[11] E. L. Deci and R. M. Ryan, "Self-determination theory: A macrotheory of human motivation, development, and health.," Can. Psychol. Can., vol. 49, no. 3, p. 182, 2008.

[12] A. K. Przybylski, C. Scott, and R. M. Ryan, "A motivational model of video game engagement," Rev. Gen. Psychol., vol. 14, no. 2, pp. 154-166, 2010.

[13] R. J. Vallerand et al., "Les passions de l'ame: on obsessive and harmonious passion.," J. Pers. Soc. Psychol., vol. 85, no. 4, p. 756, 2003.

[14] C. K. J. Wang, A. Khoo, W. C. Liu, and S. Divaharan, "Passion and intrinsic motivation in digital gaming," CyberPsychology Behav., vol. 11, no. 1, pp. 39-45, 2008.

[15] B. Bostan and S. Öğüt, "In pursuit of optimal gaming experience: challenges and difficulty levels," in Communication présentée à l'Entertainment= Emotion Conference (Benasque: Centro de Ciencias de Benasque Pedro Pascual (CCBPP)), 2009.

[16] B. Shneiderman, "Direct manipulation for comprehensible, predictable and controllable user interfaces," in Proceedings of the 2nd international conference on Intelligent user interfaces, 1997, pp. 33-39.

[17] H. L. O'Brien and E. G. Toms, "What is user engagement? A conceptual framework for defining user engagement with technology," J. Am. Soc. Inf. Sci. Technol., vol. 59, no. 6, pp. 938-955, 2008.

[18] E. A. Boyle, T. M. Connolly, T. Hainey, and J. M. Boyle, "Engagement in digital entertainment games: A systematic review," Comput. Human Behav., vol. 28, no. 3, pp. 771-780, 2012.

[19] J. L. Sherry, "Flow and Media Enjoyment," Commun. Theory, vol. 14, no. 4, pp. 328-347, 2004.

[20] P. Sweetser and P. Wyeth, "GameFlow: A Model for Evaluating Player Enjoyment in Games," Comput. Entertain., vol. 3, no. 3, pp. 3-3, 2005.

[21] C. Jennett et al., "Measuring and defining the experience of immersion in games," Int. J. Hum. Comput. Stud., vol. 66, no. 9, pp. 641-661, 2008.

[22] J. L. Sherry, K. Lucas, B. S. Greenberg, and K. Lachlan, "Video game uses and gratifications as predictors of use and game preference," Play. video games Motiv. responses, consequences, vol. 24, pp. 213-224, 2006.

[23] M. Jennings, "Theory and models for creating engaging and immersive ecommerce websites," in Proceedings of the 2000 ACM SIGCPR conference on Computer personnel research, 2000, pp. 77-85.

[24] B. Laurel, Computers as theatre. Addison-Wesley, 2013.

[25] P. Vorderer, T. Hartmann, and C. Klimmt, "Explaining the Enjoyment of Playing Video Games: The Role of Competition," in Proceedings of the Second International Conference on Entertainment Computing, 2003, pp. $1-9$.

[26] J. H. Brockmyer, C. M. Fox, K. A. Curtiss, E. McBroom, K. M. Burkhart, and J. N. Pidruzny, "The development of the Game Engagement Questionnaire: A measure of engagement in video game-playing," J. Exp. Soc. Psychol., vol. 45, no. 4, pp. 624-634, 2009.

[27] H. L. O'Brien and E. G. Toms, "The development and evaluation of a survey to measure user engagement," J. Am. Soc. Inf. Sci. Technol., vol. 61, no. 1, pp. 50-69, 2010.

[28] E. N. Wiebe, A. Lamb, M. Hardy, and D. Sharek, "Measuring engagement in video game-based environments: Investigation of the User Engagement Scale," Comput. Human Behav., vol. 32, pp. 123-132, 2014.

[29] J. Kawale, A. Pal, and J. Srivastava, "Churn prediction in MMORPGs: A social influence based approach," in Computational Science and Engineering, 2009. CSE'09. International Conference on, 2009, vol. 4, pp. $423-428$.

[30] E. G. Castro and M. S. G. Tsuzuki, "Churn Prediction in Online Games Using Players' Login Records: A Frequency Analysis Approach," IEEE Trans. Comput. Intell. AI Games, vol. 7, no. 3, pp. 255-265, 2015.

[31] F. Hadiji, R. Sifa, A. Drachen, C. Thurau, K. Kersting, and C. Bauckhage, "Predicting player churn in the wild," in 2014 IEEE Conference on 
Computational Intelligence and Games, 2014, pp. 1-8.

[32] B. G. Weber, M. John, M. Mateas, and A. Jhala, "Modeling Player Retention in Madden NFL 11.," in IAAI, 2011.

[33] P. Cairns, A. L. Cox, M. Day, H. Martin, and T. Perryman, "Who but not where: The effect of social play on immersion in digital games," Int. J. Hum. Comput. Stud., vol. 71, no. 11, pp. 1069-1077, 2013.

[34] R. (MUSE L. Bartle, "Hearts, Clubs, Diamonds, Spades: Players who suit MUDs," J. MUD Res., vol. 6, no. 1, p. 39, 1996.

[35] N. Yee, "Motivations for Play in Online Games," CyberPsychology Behav, vol. 9, no. 6, pp. 772-775, Dec. 2006.

[36] K. Christoph, H. Dorothée, and V. Peter, "The video game experience as 'true' identification: A theory of enjoyable alterations of players' selfperception," Commun. Theory, vol. 19, no. 4, pp. 351-373, Nov. 2009.

[37] D. Zillmann, "The psychology of suspense in dramatic exposition," Suspens. Conceptualizations, Theor. Anal. Empir. Explor., pp. 199-231, 1996.

[38] M. C. Green, T. C. Brock, and G. F. Kaufman, "Understanding media enjoyment: The role of transportation into narrative worlds," Commun. Theory, vol. 14, no. 4, pp. 311-327, 2004.

[39] J. Cohen, "Defining Identification: A Theoretical Look at the Identification of Audiences with Media Characters," Mass Commun. Soc., vol. 4, no. 3, pp. 245-264, 2001.

[40] D. Hefner, C. Klimmt, and P. Vorderer, "Identification with the Player Character as Determinant of Video Game Enjoyment," Entertain. Comput. - ICEC 2007, vol. 4740, no. March 2016, pp. 39-48, 2007.

[41] N. Ducheneaut, N. Yee, E. Nickell, and R. J. Moore, "The Life and Death of Online Gaming Communities : A Look at Guilds in World of Warcraft," Distribution, vol. In Press, pp. 839-848, 2007.

[42] R. B. Rubin and M. P. McHugh, "Development of parasocial interaction relationships," J. Broadcast. Electron. Media, vol. 31, no. 3, pp. 279-292, 1987.

[43] R. Gómez, "Los programas más caros de TVE," El País, 2013. [Online]. Available: http://cultura.elpais.com/cultura/2013/04/12/ television/1365796815_355916.html.

[44] M. Coates, "Kolmogorov-Smirnov test vs Mann Whitney test for unpaired hypothesis testing?," Analyticbridge, 2009. [Online]. Available: http:// www.analyticbridge.com/forum/topics/kolmogorovsmirnov-test-vsmann.

[45] N. Lovell, "ARPDAU," Gamesbrief.com, 2012. [Online]. Available: http://www.gamesbrief.com/2012/09/arpdau/.

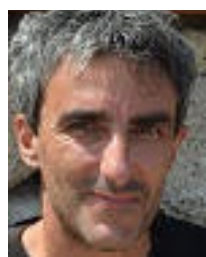

\section{Fernando De Rada}

Fernando De Rada is the Advanced Interfaces Director at Singular, an international provider of technology solutions that helps companies harness and leverage today's most cutting edge digital technologies to create value and grow. $\mathrm{He}$ received the degree in Physical Sciences from the Autonomous University of Madrid in 2003, and got his postgraduate Master in Image, Publicity and Corporate Identity from the UCJC in 2014. Over 25 years of experience as entrepreneur and senior executive in mobile, gaming and digital media, since the late 1980 s has founded and managed different companies leading multidisciplinary teams with a verifiable track record of remarkable results. He has been managing several national research projects, in the fields of Big Data, healthcare, mobile and visual technologies. He is also member of the Spanish Interactive Arts and Sciences Academy, and has been awarded in 2014 with the Prize for a Professional Career by Retro Madrid and AUIC.

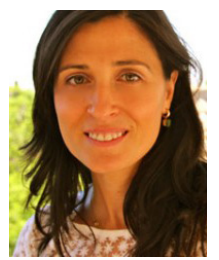

Asuncion Mochon

Asuncion Mochon holds a degree in Economics by Universidad Autonoma de Madrid and a PhD degree from UNED, where she got a tenure and is currently associate professor at the Department of Applied Economics and Economic History. She teaches graduate and undergraduate courses and has high experience in e-learning. Her research focuses on economic human behaviour and optimal

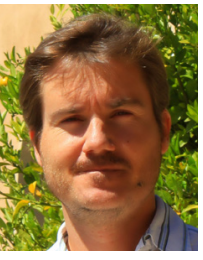

Yago Saez

Yago Saez received the degree in computer engineering in 1999. He got his Ph.D. in Computer Science (Software Engineering) from the Universidad Politecnica de Madrid, Spain, in 2005. Since 2007 till 2015 he was vice-head of the Computer Science Department from the Carlos III University of Madrid, where he got a tenure and is nowadays associate professor. He belongs to the Evolutionary Computation, Neural Networks and Artificial Intelligence research group (EVANNAI) and member of the IEEE Computational Finance and Economics Technical committee.

strategies. 